\title{
Effectiveness of adding dopamine agonist therapy to long-acting somatostatin analogues in the management of acromegaly
}

\author{
Dinesh Selvarajah, Jonathan Webster, Richard Ross and John Newell-Price \\ Division of Clinical Sciences North, University of Sheffield, Northern General Hospital, Sheffield S5 $7 A U$, UK \\ (Correspondence should be addressed to J Newell-Price; Email: j.newellprice@sheffield.ac.uk)
}

\begin{abstract}
Background: The excess mortality and morbidity associated with acromegaly are secondary to prolonged elevation of GH and IGF-I. Vigorous control of these biochemical parameters results in improved morbidity and mortality. Somatostatin analogues (SAs) allow adequate control of GH and IGF-I in approximately $65 \%$ of subjects, leaving a significant cohort uncontrolled. Dopamine agonists (DAs), a cheap alternative to SAs, allow control of GH and IGF-I in less than $20 \%$ of patients with acromegaly. Aims: To assess the effectiveness of adding DA therapy to SA in the biochemical control of acromegaly. Subjects: One hundred and twenty cases from the Sheffield Acromegaly Register were reviewed; 24 $(20 \%)$ did not require medical treatment following pituitary surgery alone; $16(13 \%)$ had safe $\mathrm{GH}$ levels following surgery and radiotherapy; and 58 (48\%) required medical treatment despite having had surgery, radiotherapy or both. The remaining $22(18 \%)$ received only medical treatment.

Methods: In nine subjects a DA (three bromocriptine, six cabergoline) was added to an SA to control active disease. GH day curves and IGF-I levels were compared before and after the addition of a DA to existing SA treatment. All were on stable maximum-dose treatment with an SA, with inadequate biochemical control prior to addition of DA therapy. Mean duration of treatment on a DA before biochemical assessments were made was 10.3 months. Six subjects had previously been treated with either transsphenoidal surgery, radiotherapy or both. In three subjects SA was the primary therapy. Results: All subjects exhibited a fall in median GH and IGF-I levels. Introduction of a DA resulted in a $36.1 \%$ reduction in median GH levels ( 8.3 vs $5.3 \mathrm{mIU} / \mathrm{l} ; P=0.008)$ on a $\mathrm{GH}$ day curve and a $35.2 \%$ reduction in IGF-I levels ( $387.2 \mathrm{vs} 251.0 \mu \mathrm{g} / \mathrm{l} ; P=0.018)$. Only four subjects had elevated prolactin levels prior to the addition of a DA (>368 $\mathrm{mIU} / \mathrm{l})$.

Conclusion: Addition of DAs to SAs is of benefit in the biochemical control of acromegaly and should be considered in those inadequately controlled. Furthermore, the beneficial effects of DAs occur even when pre-treatment prolactin levels are within the normal range.
\end{abstract}

European Journal of Endocrinology 152 569-574

\section{Introduction}

Acromegaly results in premature death $(1-4)$. It is most frequently caused by a pure growth hormone (GH)-secreting pituitary somatotroph adenoma (5). Insulin-like growth factor-I (IGF-I) mediates many of the biological actions of $\mathrm{GH}$ (6). The morbidity and excess mortality associated with acromegaly is a consequence of excess GH and IGF-I levels (7). The important markers of outcome in the treatment of acromegaly are the most recent GH and IGF-I levels, with the mortality rate being comparable to the general population of the UK if mean GH levels are less than $2.5 \mu \mathrm{g} / \mathrm{l}(8)$. Normalisation of IGF-I levels is also associated with a return of mortality to normal (9). Hence, the main goal of treatment should be to achieve safe GH/IGF-I levels (10).

Transsphenoidal surgery remains the primary treatment for acromegaly in most centres. Surgical outcomes depend on a variety of factors including the size of the tumour, local invasiveness and the skill of the surgeon (11). As a result there is clearly a wide disparity in outcomes amongst different centres. Furthermore, as 70\% of tumours are macroadenomas most subjects are not cured by surgery and require subsequent medical treatment (12). Fractionated external beam radiotherapy is another treatment option, which is effective in lowering $\mathrm{GH}$. Overall $\mathrm{GH}$ levels decline exponentially from the beginning of treatment. However, this is a slow process and may take up to 10 years for $50 \%$ of subjects to reach safe $\mathrm{GH}$ levels $(<5 \mathrm{mU} / \mathrm{l})$ and a normal IGF-I (13). Hence, radiotherapy is usually an adjunct for aggressive tumours after unsuccessful treatment. Stereotactic radiosurgery, on the other hand, is single-dose treatment that is an effective method of delivering radiation treatment to $\mathrm{GH}$-secreting tumours, whilst minimising the risk of radiation to surrounding tissues. Available data suggest that pituitary hypersecretion may resolve 
faster with stereotactic radiosurgery, but long-term data are still awaited $(14,15)$.

Recent advances in medical treatment have raised the prospect of obtaining biochemical control in virtually every subject, with consequent relief of symptoms and restoration of life expectancy to normal. In the past decade dopamine agonists (DAs) have been superseded by somatostatin analogues (SAs) as the mainstay of medical treatment for acromegaly. In particular, the long-acting formulations of octreotide and lanreotide allow dosing at intervals from 2 to 6 weeks, and have become the primary means of medical treatment. These later agents are, however, expensive and at best normalise the GH/IGF-I axis in approximately $65 \%$ of individuals, leaving a significant cohort uncontrolled $(16,17)$. DAs on the other hand are comparatively inexpensive and may still have a role as combination treatment with SAs in achieving safe GH/IGF-I levels in those partial/non-responders to SAs (18). This study investigated the effectiveness in clinical practice of the addition of a DA to an SA, in the routine treatment of inadequately controlled acromegaly.

\section{Materials and methods}

A retrospective review was performed on subjects in the Sheffield Acromegaly Register. This register contains the clinical details of all subjects referred to the Sheffield Teaching Hospitals with acromegaly. Date of diagnosis, details of surgery, radiotherapy and commencing/ discontinuing medical treatment were noted. Mean $\mathrm{GH}$ levels measured as five samples over the day, IGF-I and prolactin levels performed to assess effects of interventions at various time points during an individual subject's care were noted. Our intention was to specifically assess the effect of the addition of a DA to SA therapy in those individuals who had not fully responded to SA therapy alone. Thus, from this dataset, all subjects who had had a DA added to pre-existing SA treatment because of inadequate biochemical control when on the SA alone were identified, and are, therefore, a consecutive series of patients. To minimise selection bias any subject who had previously received DA therapy prior to SA treatment was not included.

The effect of this combination treatment was analysed. GH day curves and IGF-I levels were compared before and after the commencement of combined DA and SA treatment.

\section{Assays}

GH (Immulite Growth Hormone; DPC, Los Angeles, CA, USA), prolactin (Bayer Centaur, previously Abbot AxSym; Newbury, Berks, UK) and IGF-I (Nichols, San Juan de Capistrano, CA, USA) were assayed by immunochemiluminescence and IRMA after acid-ethanol extraction respectively. A reference range study performed with DPC's Immulite GH kit on 62 samples from apparently healthy adults yielded the following results: an absolute range for $\mathrm{GH}$ of $0.06-5.0 \mathrm{ng} / \mathrm{ml}$. The GH assay has a calibration range of up to $40 \mathrm{ng} / \mathrm{ml}$. To convert $\mathrm{ng} / \mathrm{ml}$ to $\mathrm{mIU} / \mathrm{l}$ in terms of the World Health Organization's International Reference Preparation Number 80/505, multiply by 2.6. Intraassay and inter-assay coefficients of variation for the GH assay were $5.3-6.5$ and $5.5-6.1 \%$ respectively. Normal ranges for the IGF-I assay $(\mu \mathrm{g} / \mathrm{l})$ are at $20-24$ years, 116-447 (female), 133-498 (males); at 2640 years, 96-302 (females and males); at 40-50 years, 80-276 (males and females); at 50-60 years, 65-251 (male and females); at 60-70 years, 52227 (male and females); at 70-80 years, 40-204 (males and females); and at $>80$ years, 29-182 (males and females). Intra-assay and inter-assay coefficients of variation for the IGF-I assay were 3.3-4.6 and $9.3-15.8 \%$ respectively. Normal ranges for prolactin used for males and females over the age of 18 years were $45-375$ and 59-619 $\mathrm{mIU} / \mathrm{l}$ respectively.

\section{Statistical analysis}

All analysis was performed using the statistical package SPSS 11.1. Baseline characteristics and outcome variables (GH and IGF-I levels) were described as means and s.E.M. for normally distributed variables and as medians and 25th and 75th percentiles for variables with a skewed distribution. The Kolmogorov-Smirnov test was used to assess normality of distribution. The Wilcoxon signed-ranks test was used to test the null hypothesis that two related medians are the same. The relationship between prolactin levels at diagnosis and change in GH and IGF-I levels on combination therapy was analysed using linear regression. All statistical tests were two tailed and $P$ values of less than 0.05 were considered significant.

\section{Results}

A total of 120 cases from the Sheffield Acromegaly Register were reviewed. Of these subjects 24 out of $120(20 \%)$ did not require medical treatment following pituitary surgery alone; 16 out of 120 (13\%) had safe GH levels following surgery and radiotherapy and 58 out of $120(48 \%)$ required medical treatment despite having had surgery, radiotherapy or both. The remaining 22 out of $120(18 \%)$ received only medical treatment (Fig. 1).

In nine subjects a DA (three bromocriptine and six cabergoline) was added to SA to control active disease. These subjects had not received DA therapy previously. The demographics of the subjects are shown in Table 1. Mean (S.E.M.) age of subjects was 53.1 (7.1) years. Individual GH and IGF-I levels before and after addition of DA are shown in Table 2. All were on a 


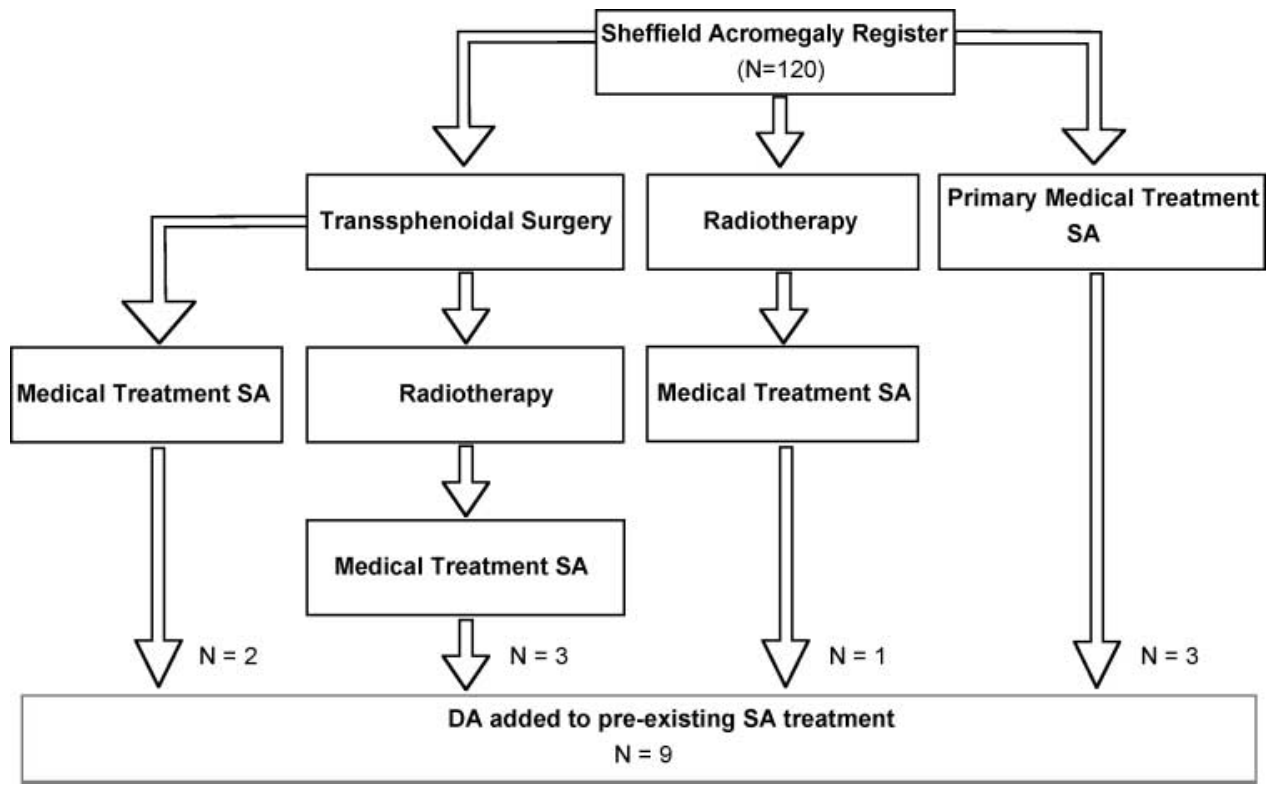

Figure 1 Flow diagram tracing the management outline of acromegalic subjects. SA, somatostatin analogue; DA, dopamine agonist. stable maximum-tolerated dose of SA treatment for an average of 18.3 (4.8) months, with inadequate biochemical control prior to addition of DA treatment. The mean dose of cabergoline and bromocriptine used was $1.1 \mathrm{mg}$ per week and $4.2 \mathrm{mg}$ three times per day, respectively. In no subject was the DA withdrawn as a result of intolerable side-effects. Three subjects (subjects A, B and G) were treated with medical therapy only and

Table 1 Subject demographics and baseline characteristics.

\begin{tabular}{lccccccccc}
\hline & \multicolumn{1}{c}{ Subject } \\
\cline { 2 - 10 } & A & B & C & D & E & F & G & H \\
\hline Age (years) & 63 & 82 & 42 & 49 & 71 & 30 & 79 & 37 & 25 \\
RT (years before) & None & None & 8.0 & 9.0 & 16.0 & 5.0 & None & None & None \\
Surgery & None & None & TPS & None & TPS & TPS & None & TPS & TPS \\
SA ( $\mu$ g) & LAR 30 & LAR 30 & LAR 30 & LAR 30 & LAR 30 & Oct 500 & LAR 30 & Oct 400 & LAR 30 \\
CB mg (per week) & 1.0 & - & 1.0 & - & - & - & 1.5 & - & 1.0 \\
BR mg (tds) & - & 10 & - & 2.5 & 5.0 & 2.5 & - & 1.0 & - \\
Prolactin (mlU/l) & 6310 & 53 & 154 & 2853 & N/A & 383 & 143 & 1570 & 626 \\
\hline
\end{tabular}

TPS, transsphenoidal surgery; RT, three-field external beam fractionated radiotherapy at years from assessment made on combination therapy; N/A, not available; LAR 30, depot octreotide $30 \mu \mathrm{g}$ monthly; Oct 400, octreotide $400 \mu \mathrm{g}$ three times a day (tds); Oct 500, octreotide $500 \mu \mathrm{g}$ tds; CB, cabergoline; $\mathrm{BR}$, bromocriptine.

Table 2 GH (mIU/l) IGF-I ( $\mu \mathrm{g} / \mathrm{l})$ levels and duration (months) pre- and post-addition of dopamine agonist to somatostatin analogue treatment.

\begin{tabular}{|c|c|c|c|c|c|c|c|}
\hline \multirow[b]{2}{*}{ Subject } & \multicolumn{3}{|c|}{ Somatostatin analogue only } & \multicolumn{3}{|c|}{$\begin{array}{c}\text { Somatostatin analogue and dopamine } \\
\text { agonist combination }\end{array}$} & \multirow[b]{2}{*}{ IGF-I normal range } \\
\hline & Duration & $\mathrm{GH}$ & IGF-I & Duration & $\mathrm{GH}$ & IGF-I & \\
\hline A & 20 & 6.3 & 322 & 13 & 2.7 & 206 & $52-227$ \\
\hline B & 51 & 11.3 & 297 & 11 & 8.3 & 197 & $26-182$ \\
\hline C & 17 & 6.5 & 387.2 & 23 & 2.4 & 211 & $80-276$ \\
\hline D & 23 & 18.3 & 505.8 & 29 & 3.3 & 255 & $80-276$ \\
\hline E & 24 & 6.5 & 698 & 7 & 6.2 & 290 & $40-204$ \\
\hline $\mathrm{F}$ & 1 & 12.9 & $\mathrm{~N} / \mathrm{A}$ & 14 & 4.8 & $\mathrm{~N} / \mathrm{A}$ & N/A \\
\hline G & 13 & 8.3 & 302 & 11 & 6.0 & 251 & $40-204$ \\
\hline $\mathrm{H}$ & 6 & 93 & $\mathrm{~N} / \mathrm{A}$ & 11 & 46 & $\mathrm{~N} / \mathrm{A}$ & N/A \\
\hline 1 & 10 & 6.4 & 680 & 10 & 5.3 & 608 & $127-360$ \\
\hline & $18.3(4.8)^{\#}$ & $8.3(6.4-15.6)^{+}$ & $387.2(302-680)^{+}$ & $14.3(2.3)^{\#}$ & $5.3(3.0-7.3)^{+}$ & $251(206-290)^{+}$ & \\
\hline
\end{tabular}

${ }^{\#}$ Mean and S.E.M. ${ }^{+}$Median and 25 th-75th percentile range. 


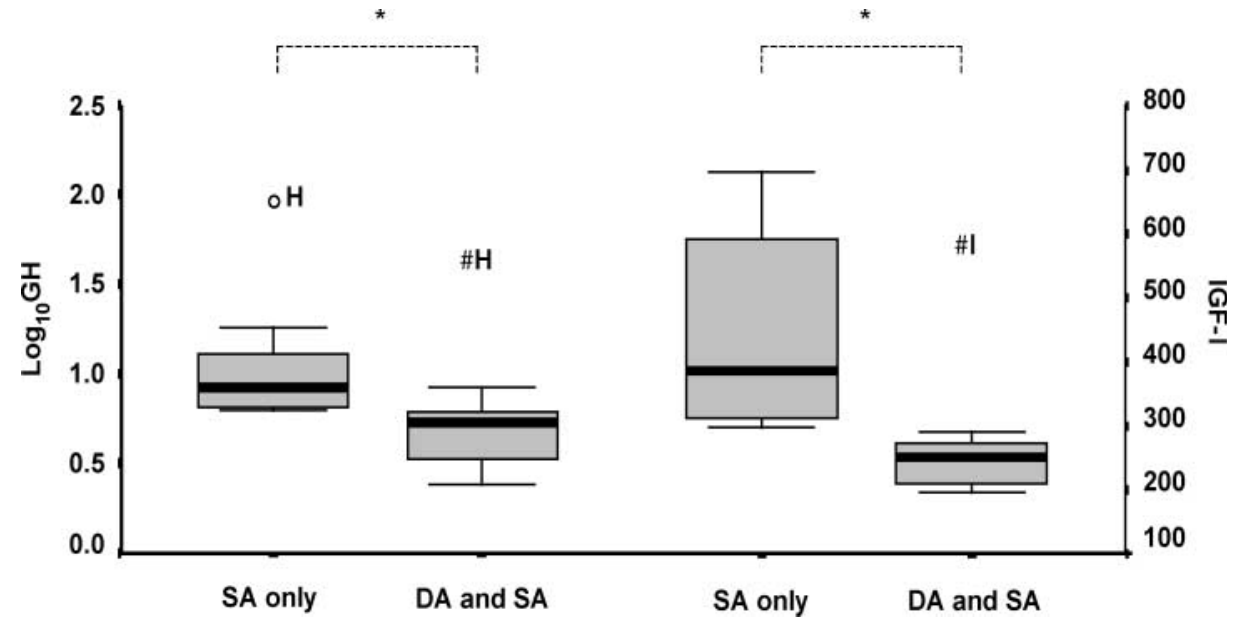

Figure 2 Boxplots for $\log _{10} \mathrm{GH}$ $(\mathrm{mlU} / \mathrm{l})$ and IGF-I $(\mu \mathrm{g} / \mathrm{l})$ levels on somatostatin analogue (SA) only and on combination therapy (dopamine agonist (DA) and SA). Each boxplot depicts the median, the 25th and 75th percentiles and the minimum and maximum observed values that are not statistically outlying. The two left hand boxes are $\mathrm{GH}$ data and the two right hand boxes are IGF-I data. Outlying values: $\mathrm{H}, \mathrm{GH}$ level for subject $\mathrm{H}$ on SA only; \#H, GH level for subject $\mathrm{H}$ on DA and SA; \#I IGF-I level for subject I while on DA and SA. ${ }^{*} P<0.05$. six had either transsphenoidal surgery, or radiotherapy or both. In four subjects (subjects C, D, E and F) the mean duration between radiotherapy and commencement of combination treatment was 9.5 (2.3) years. In two subjects (subjects $\mathrm{F}$ and $\mathrm{H}$ ) there were insufficient data on IGF-I levels before and after addition of DA, hence they were excluded from subsequent IGF-I sub-analysis.

Before combination treatment the median (range: 25th-75th percentile) GH and IGF-I levels were $8.3 \mathrm{mIU} / \mathrm{l} \quad(6.4-15.6)$ and $387.2 \mu \mathrm{g} / \mathrm{l} \quad(302-680)$ respectively (Fig. 2). Mean duration of treatment on a DA before biochemical assessments were made was 14.3 (2.3) months. Median GH and IGF-I level on combination therapy were $5.3 \mathrm{mIU} / \mathrm{l}(3.0-7.25)$ and $251 \mu \mathrm{g} / \mathrm{l}$ (206-290) (Fig. 2).
All subjects exhibited a fall in GH and IGF-I levels post addition of DA (Fig. 3). Introduction of a DA resulted in a $36.1 \%$ reduction in median $\mathrm{GH}$ levels ( 8.3 vs $5.3 \mathrm{mIU} / \mathrm{l} ; P=0.008$ ) on a $\mathrm{GH}$ day curve and a $35.2 \%$ reduction in median IGF-I levels $(387.2$ vs $251.0 \mu \mathrm{g} / \mathrm{l} ; P=0.018$ ). Four subjects (subjects A, C, $\mathrm{D}$ and F; $44 \%$ of the whole series) reached safe $\mathrm{GH}$ levels $(<5 \mathrm{mIU} / \mathrm{l})$ and three subjects (subjects A, C and D; $33 \%$ of the whole series) had normal ageadjusted IGF-I levels.

Only four subjects (subjects A, D, H and I; 44\%) in this cohort had elevated prolactin levels (>368 mIU/l) at diagnosis. No significant correlation was found between prolactin levels at diagnosis and the fall in GH and IGF-I levels on combination therapy $(P=0.86$ and 0.75 respectively $)$.

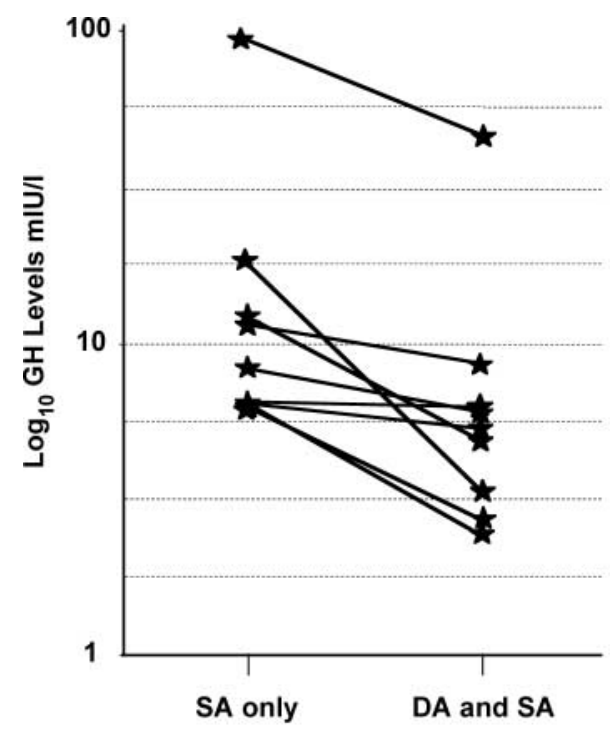

$24.1 \%$ reduction in median $\mathrm{GH}$ levels

( 8.3 vs $5.3 \mathrm{mlU} / \mathrm{l} ; P=0.008$ )

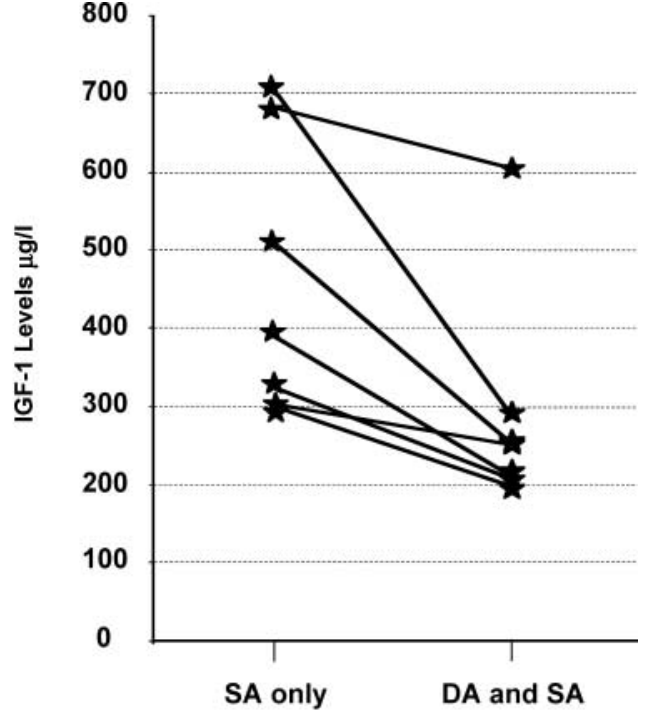

$35.2 \%$ reduction in median IGF-I levels (387.2 vs $251.0 \mu \mathrm{g} /$; $P=0.018$ )
Figure 3 Growth hormone $(\mathrm{GH})$ and IGF-I levels during somatostatin analogue (SA) treatment only and combination dopamine agonist (DA) and SA treatment. 


\section{Discussion}

No single treatment for acromegaly is completely successful in controlling the disease and all its clinical manifestations, and different treatment modalities have advantages and disadvantages $(10,19)$. In deciding upon appropriate means to achieve biochemical control and relief of clinical manifestations the risk and benefits of each treatment modality needs to be optimised for each subject (10). SA remains the mainstay of medical treatment with oral DA as a second-line agent currently advocated with coexisting hyperprolactinaemia. There are, however, limited data on the therapeutic efficacy of combined use of SA and DA therapy (20). In a recent prospective study Cozzi et al. demonstrated the efficacy of the addition of DA to SA therapy (21). Interestingly, they showed that the presence of hyperprolactinaemia was not necessary to predict a response. Our data are in keeping with this. In contrast, previous studies assessing this combination have suggested that a response was seen only in those with hyperprolactinaemia (22). From a pragmatic perspective these data suggest that a trial of combined therapy should be considered in appropriate patients whether or not the circulating prolactin is elevated. We also studied the effects of the addition of two different DAs (bromocriptine and cabergoline) and found that both showed significant therapeutic efficacy. In addition, mean cabergoline dose used was lower in our study compared with that by Cozzi et al. (21) (1.1 vs $2.6 \mathrm{mg}$ per week).

We have retrospectively analysed 120 cases of acromegaly and in nine subjects a DA was added to a stable maximum-dose treatment with SA. We assessed the effectiveness of this combined therapy in clinical practice and found that the addition of a DA to SA is of benefit in the biochemical control of acromegaly, and should be considered in those inadequately controlled. Whilst we expect that such an approach may be widespread, it is little documented. Although our study is limited by small numbers and its retrospective nature, our data add to the growing documentation of the efficacy and effectiveness of this combined therapy. Furthermore, the combined treatment appears to be well tolerated. Moreover, it gives support to the utility of such an approach in routine clinical practice, demonstrating the effectiveness of this combined therapy outside the tight confines of clinical trials. SA therapy causes at least 30\% shrinkage in pituitary tumour volume in $73 \%$ of subjects with acromegaly (23). It seems likely that the addition of DA therapy will enhance this effect, although this will need testing in long-term studies with sequential imaging. The effects seen here on the levels of GH and IGF-I could potentially relate to the previous therapy that the subjects had received. The mean duration of SA therapy was 18.3 months (range $1-51$ ) prior to the addition of the DA, with the levels of GH and IGF-I still being inadequately controlled. This makes it unlikely that the effects observed were due to the SA alone. In subjects $\mathrm{F}$ and $\mathrm{H}$, however, the duration of treatment with SA alone was 1 and 6 months, prior to the addition of DA. It is possible that the effects we have observed are simply due to the effects of SA therapy when on prolonged treatment $(23,24)$, rather than due to the extra effects of DA therapy. In these individuals, however, the daily dose of SA was 1500 and $1200 \mu \mathrm{g}$ octreotide s.c. given in three divided doses. Despite these high doses of non-depot SA their acromegaly remained inadequately controlled. Thus, it seems likely that the additional DA therapy was contributing to the beneficial effect observed. Similarly, four subjects had had pituitary radiotherapy 5-16 years before. Since radiotherapy is well documented to cause an initial exponential fall in GH (25) with levels then falling in a linear fashion, it is highly unlikely that the reduction in GH and IGF-I seen here over the short period of assessment (mean 13.3 months; range 7-29 months after the addition of DA) is caused by the previous radiotherapy.

It is possible that we could have selected those patients who were likely responders to DA therapy, but we have included analysis of all patients who had a DA added after stable SA therapy. None of these had received a DA previously. In this small cohort all appear to have responded, but it is likely that some patients will not show such a response and thus careful biochemical follow-up is needed in clinical practice to assess the effectiveness of this approach for a given patient.

Octreotide and lanreotide, the SA agents in common practice for the treatment of acromegaly bind predominantly to somatostatin receptor subtypes 2 and 5. Bromocriptine and cabergoline bind predominantly to dopamine D2 receptors. Elegant molecular analyses using fluorescent resonance energy transfer techniques have demonstrated hetero-dimerisation of somatostatin and dopamine receptors (26). It is likely that the effects seen here may involve receptor dimerisation, and synergistic action, although it may simply be the additive effect of combined therapy. Interestingly, the dose of DA used here is not very high (Table 1), which perhaps lends support to the effects being mediated by receptor dimerisation. Cozzi et al. (21) used higher doses, but the effects seen are similar in both that study and the data reported here. It is possible that the more prolonged period of administration at a lower dose achieved an effect similar to that seen for higher doses but of shorter duration. We can speculate whether addition of much higher doses could have been more effective, but this needs assessment in prospective studies.

Pegvisomant is an alternative agent for the treatment of acromegaly that blocks GH-receptor signalling, and hence lowers IGF-I and is a highly effective therapy for acromegaly, which has been shown to lower IGF-I in those not controlled on SA (27). Although now licensed for the therapy of acromegaly, pegvisomant is 
extremely expensive and this limits its widespread use. The data presented here, and those of others, give strong support to the practice of adding DA therapy to those subjects inadequately treated with an SA, and then assessing if this improves control $(18,21)$.

In conclusion, we have confirmed the effectiveness of adding a DA treatment in subjects on stable SA therapy with inadequate control of disease. The effectiveness of this approach, however, needs assessment in each individual patient in whom it is used.

\section{Acknowledgements}

The authors would like to acknowledge the contribution of the endocrine nurses (Sister Betty Roberts, Sister Vicky Ibbotson, Staff Nurse Anita Doane and Sister Kay Dunkley) and Jayne Cunningham for assistance in sourcing and identifying subjects.

\section{References}

1 Alexander L, Appleton D, Hall R, Ross WM \& Wilkinson R. Epidemiology of acromegaly in the Newcastle region. Clinical Endocrinology $19801271-79$

2 Bengtsson BA, Eden S, Ernest I, Oden A \& Sjogren B. Epidemiology and long-term survival in acromegaly. A study of 166 cases diagnosed between 1955 and 1984. Acta Medica Scandinavica $1988223327-335$.

3 Wright AD, Hill DM, Lowy C \& Fraser TR. Mortality in acromegaly. Quarterly Journal of Medicine 197039 1-16.

4 Orme SM, McNally RJ, Cartwright RA \& Belchetz PE. Mortality and cancer incidence in acromegaly: a retrospective cohort study. United Kingdom Acromegaly Study Group. Journal of Clinical Endocrinology and Metabolism 199883 2730-2734.

5 Melmed S. Acromegaly. New England Journal of Medicine 1990 $322966-977$.

6 Cunningham BC, Ultsch M, De Vos AM, Mulkerrin MG, Clauser KR \& Wells JA. Dimerization of the extracellular domain of the human growth hormone receptor by a single hormone molecule. Science 1991254 821-825.

7 Melmed S, Ho K, Klibanski A, Reichlin S \& Thorner M. Recent advances in pathogenesis, diagnosis, and management of acromegaly. Journal of Clinical Endocrinology and Metabolism $1995803395-3402$.

8 Bates AS, Van't Hoff W, Jones JM \& Clayton RN. An audit of outcome of treatment in acromegaly. Quarterly Journal of Medicine $199386293-299$.

9 Holdaway IM, Rajasoorya RC \& Gamble GD. Factors influencing mortality in acromegaly. Journal of Clinical Endocrinology and Metabolism 200489 667-674.

10 Consensus statement: benefits versus risks of medical therapy for acromegaly, Acromegaly Therapy Consensus Development Panel. American Journal of Medicine 199497 468-473.

11 Ahmed S, Elsheikh M, Stratton IM, Page RC, Adams CB \& Wass JA. Outcome of transphenoidal surgery for acromegaly and its relationship to surgical experience. Clinical Endocrinology 1999 $50561-567$.

12 Abosch A, Tyrrell JB, Lamborn KR, Hannegan LT, Applebury CB \& Wilson CB. Transsphenoidal microsurgery for growth hormone-secreting pituitary adenomas: initial outcome and long-term results. Journal of Clinical Endocrinology and Metabolism 199883 3411-3418.
13 Wass JA, Laws ER Jr, Randall RV \& Sheline GE. The treatment of acromegaly. Clinical Endocrinology and Metabolism 198615 $683-707$.

14 Attanasio R, Epaminonda P, Motti E, Giugni E, Ventrella L, Cozzi R, Farabola M, Loli P, Beck-Peccoz P \& Arosio M. Gamma-knife radiosurgery in acromegaly: a 4-year follow-up study. Journal of Clinical Endocrinology and Metabolism 200388 3105-3112.

15 Nawaz A, Newton D, Sanderman D, Rowe J, Ross RJM, Kemeny A \& Newell-Price J. Gamma knife stereotactic radiosurgery for acromegaly. Endocrine Abstracts 20047 OC27.

16 Lancranjan I \& Atkinson AB. Results of a European multicentre study with Sandostatin LAR in acromegalic patients. Sandostatin LAR Group. Pituitary 19991 105-114.

17 Melmed S. Tight control of growth hormone: an attainable outcome for acromegaly treatment. Journal of Clinical Endocrinology and Metabolism 199883 3409-3410.

18 Marzullo P, Ferone D, Di Somma C, Pivonello R, Filippella M, Lombardi G \& Colao A. Efficacy of combined treatment with lanreotide and cabergoline in selected therapy-resistant acromegalic patients. Pituitary 19991 115-120.

19 Melmed S, Jackson I, Kleinberg D \& Klibanski A. Current treatment guidelines for acromegaly. Journal of Clinical Endocrinology and Metabolism $1998 \mathbf{8 3} 2646-2652$.

20 Jaffe CA \& Barkan AL. Treatment of acromegaly with dopamine agonists. Endocrinology and Metabolism Clinics of North America $199221713-735$.

21 Cozzi R, Attanasio R, Lodrini S \& Lasio G. Cabergoline addition to depot somatostatin analogues in resistant acromegalic patients: efficacy and lack of predictive value of prolactin status. Clinical Endocrinology $200461209-215$.

22 Marzulo P, Ferone D, Di Somma C, Pivonello R, Filippella M, Lombardi G \& Colao A. Efficacy of combined treatment with lanreotide and cabergoline in selected therapy-resistant acromegalic patients. Pituitary 19991 115-120.

23 Bevan JS, Atkin SL, Atkinson AB, Bouloux PM, Hanna F, Harris PE, James RA, McConnell M, Roberts GA, Scanlon MF, Stewart PM, Teasdale E, Turner HE, Wass JA \& Wardlaw JM. Primary medical therapy for acromegaly: an open, prospective, multicenter study of the effects of subcutaneous and intramuscular slow-release octreotide on growth hormone, insulin-like growth factor-I, and tumor size. Journal of Clinical Endocrinology and Metabolism 200287 4554-4563.

24 Cozzi R, Attanasio R, Montini M, Pagani G, Lasio G, Lodrini S, Barausse M, Albizzi M, Dallabonzana D \& Pedroncelli AM. Four-year treatment with octreotide-long-acting repeatable in 110 acromegalic patients: predictive value of short-term results? Journal of Clinical Endocrinology and Metabolism $2003 \mathbf{8 8}$ 3090-3098.

25 Wass JA. Radiotherapy in acromegaly: a protagonist's viewpoint. Clinical Endocrinology 200358 128-131.

26 Rocheville M, Lange DC, Kumar U, Patel SC, Patel RC \& Patel YC. Receptors for dopamine and somatostatin: formation of heterooligomers with enhanced functional activity. Science $2000 \mathbf{2 8 8}$ $154-157$.

27 Trainer PJ, Drake WM, Katznelson L, Freda PU, Herman-Bonert V, van der Lely AJ, Dimaraki EV, Stewart PM, Friend KE, Vance ML, Besser GM, Scarlett JA, Thorner MO, Parkinson C, Klibanski A, Powell JS, Barkan AL, Sheppard MC, Malsonado M, Rose DR, Clemmons DR, Johannsson G, Bengtsson BA, Stavrou S, Kleinberg DL, Cook DM, Phillips LS, Bidlingmaier M, Strasburger CJ, Hackett S, Zib K, Bennett WF \& Davis RJ. Treatment of acromegaly with the growth hormone-receptor antagonist pegvisomant. New England Journal of Medicine 2000 $3421171-1177$.

Received 19 December 2004

Accepted 13 January 2005 